\title{
Mediando o regime militar: as narrativas de 0 Globo sobre os aniversários da Revolucão de 64 durante 0 governo Geisel
}

\section{RESUMO}

Este texto discute a cobertura concedida pelo jornal O Globo às cerimônias de aniversário da "revolução" de 1964, durante o governo do presidente Ernesto Geisel. A partir da análise da narrativa do jornal, que é mais complexa do que tem sido considerada até a atualidade, identificamos uma mudança no papel que os próprios jornalistas se atribuem ao fazerem o seu trabalho e que se torna explícita nos textos que produzem. Discutir essa mudança é o objetivo deste trabalho.

\section{PALAVRAS-CHAVE}

\section{O Globo}

Regime militar

Jornalismo

Drawing on the military regime: the narratives of $\mathrm{O}$ Globo about Revolution of 1964 anniversary ceremonies during Geisel government

\section{ABSTRACT}

This paper discusses the coverage provided by the newspaper $O$ Globo to the anniversary ceremonies of the "revolution of 1964" during President Ernesto Geisel government. From the analysis of the newspaper narrative, which is more complex than has been considered until today, we have identified a change in the role that journalists themselves fall to do their job and that becomes explicit in the texts they produce. Our aim is to discuss this change.

\section{KEYWORDS}

O Globo

Military regimen

Journalism

\section{Juliana Gagliardi de Araujo}

Mestranda do Programa de Pós-Graduação em Comunicação da UFF/ $R J / B R$

jugagliardi@gmail.com

\author{
Afonso de Albuquerque \\ Professor do Programa de Pós-Graduação em Comunicação da UFF/ \\ $R J / B R$ \\ afonsoal@uol.com.br
}

Neste artigo investigamos de que modo o jornal O Globo cobriu as solenidades de comemoração da instauração do regime militar - realizadas anualmente a cada dia 31 de março - durante o governo do presidente Ernesto Geisel (1974-1979). A discussão apresentada constitui uma pesquisa ainda em andamento e que se propõe a compreender o tema durante todo o período de vigência do regime militar (1964-1985). Como regra geral, os estudos realizados sobre a atuação da imprensa durante o regime militar têm enfocado o tema principalmente sob dois pontos de vista, relativos à: 1) censura realizada pelo regime militar (Dassin, 1984; Jorge, 1989; Soares, 1989; Aquino, 1999; Kushnir, 2004) e 2) resistência ou a colaboração com o regime, por parte dos jornalistas e veículos noticiosos (Aquino, 1999; Smith, 2000; Kucinski, 2003; Kushnir, 2004). Acreditamos que, não obstante a sua importância, as duas perspectivas não cobrem todos os aspectos relevantes da questão. A ênfase na censura, naturalmente, dá conta daquilo que os jornais não puderam dizer, por conta de uma imposição externa. O foco na questão da resistência ou adesão, por outro lado, traz o risco de alimentar um olhar maniqueísta sobre o período, e fazer da distinção entre bons e maus, heróis e vilões, o objetivo fundamental da pesquisa. Em particular, estas perspectivas dizem pouco sobre a mediação que os jornalistas e organizações jornalísticas desempenharam entre o regime, de um lado, e o seu público de leitores, do outro, durante o regime militar.

A escolha da principal cerimônia de comemoração do regime não se faz por acaso. Nela, o regime justifica o seu presente em relação ao marco fundador representado pela "Revolução de 64". Contudo, para adquirir dimensão nacional, 


\section{essas comemorações finham que contar com a mediação dos veículos jornalísticos, 0 que abria para estes uma margem de aufonomia para a sua afuação. 0 quanto os jornalistas efetivamente exerciam esta autonomia, e de que modo eles o faziam?}

A análise das cerimônias em questão oferece um ângulo de abordagem interessante para dar conta desta questão. Dois aspectos, na nossa análise, merecem considerações suplementares: o primeiro diz respeito à seleção da cobertura do jornal $O$ Globo e o segundo se refere à escolha das cerimônias realizadas durante o governo de Ernesto Geisel como objetos da nossa análise.

$O$ Globo era, na época, um dos jornais com maior circulação do país, um representante do que se convencionou chamar na época de a grande imprensa, e se caracterizou por sua atitude consistentemente simpática ao regime. Ao mesmo tempo, o jornal se caracterizava pela presença de um número significativo de jornalistas comunistas em suas fileiras, com o conhecimento dos diretores do jornal (Abreu, Lattman-Weltman \& Rocha, 2003; Albuquerque \& Silva, 2009), a tal ponto que se tornou folclórica a frase "dos meus comunistas, cuido eu" supostamente dita pelo dono do jornal, Roberto Marinho, ao ministro da Justiça Armando Falcão (Andrade, 2003). Curiosamente, a presença de um número expressivo de comunistas no jornal não parece ter influenciado a sua cobertura, de modo a aproximá-la de uma agenda esquerdista ou, mesmo, de oposição ao regime. Ao contrário, os comunistas parecem ter sido bastante discretos na sua atuação profissional, sendo não raro, objetos de elogios por parte dos seus superiores a este respeito. De todo modo, fica claro que o governismo de $O$ Globo é um fenômeno mais complexo do que parece à primeira vista e que, portanto, merece estudos mais aprofundados.

Igualmente, o período do governo Geisel apresenta desafios complexos para a análise do objeto em questão. Ao contrário do que acontece com O Globo, o período tem suscitado um interesse considerável dos acadêmicos, uma vez que tem sido apontado como o marco inicial da abertura política (Duarte, 1983; Dassin, 1984; Stepan,
1986). Em particular, muitos autores destacam que o governo Geisel tenha concretamente se aproximado da imprensa com o intuito de cativar seus membros com relação à política da abertura. Ao mesmo tempo, o processo de abertura não ocorreu de modo simples ou unidirecional. Iniciativas de distensão se misturaram a outras, de caráter repressivo. Isto ocorreu em boa medida porque a instituição militar não era coesa e uniforme, mas fissurada, internamente dividida em torno de projetos diversos de governo, que opunham os militares "moderados" aos da "linha dura". Em meio a este ambiente de instabilidade política, os rituais políticos patrocinados pelo regime militar estabeleciam, ao menos em princípio, um contraponto, uma ocasião regular para expressar uma unidade institucional e de governo, embora na prática eles também pudessem servir como ocasião para explicitar tensões existentes no interior do regime e da instituição militar. No que diz respeito aos jornalistas, esta situação contribuía para tornar o ambiente instável e perigoso, como o demonstrou claramente o assassinato do jornalista Vladimir Herzog ${ }^{1}$. Nem mesmo os jornalistas com propensão ao governismo estavam totalmente seguros, pois em um contexto de divisão na base militar, não estava claro que facção triunfaria. Nestas circunstâncias, cobrir as comemorações da "Revolução de 1964" era, para os jornalistas, tanto uma obrigação quanto um risco. Analisar como os jornalistas lidaram com esta situação complexa é o objetivo deste artigo.

\section{Cafegorias de Análise}

O objetivo de nossa análise é investigar o modo como os jornalistas de $O$ Globo atuaram na cobertura da cerimônia comemorativa da "Revolução de 64", realizada anualmente no dia 31 de março. Nossa atenção não se restringe apenas ao modo como os jornalistas representaram os acontecimentos e seu significado, mas tenta dar conta do modo como eles representaram seu papel como mediadores do evento. Muito frequentemente, esta questão tem sido julgada a partir do paradigma da objetividade jornalística, tendo em vista a separação entre "fatos" e "opiniões" (Schudson, 1978; Tuchman, 1993, Chalaby, 1996). Este modelo de análise, porém, apresenta claros limites quando aplicados ao nosso objeto, por duas razões. Em primeiro lugar, a separação da descrição dos fatos e opiniões não resume a atuação dos jornalistas no âmbito da lógica da objetividade jornalística. Para além dessas duas categorias, uma terceira se impõe, relativa à interpretação dos acontecimentos, isto é, ao modo como os jornalistas produzem significado a partir dos acontecimentos que relatam, ou, dito em outros termos ao "modo como 
o mundo é incorporado em convenções narrativas inquestionáveis e despercebidas" (Schudson, 1993: 279). Mais do que meros estenógrafos dos acontecimentos, os jornalistas reivindicam desempenhar um papel mais ativo na interpretação da realidade ou, nos termos consagrados por Zelizer (2001), uma "autoridade interpretativa" sobre os acontecimentos que relatam.

Por outro lado, a objetividade jornalística pressupõe uma dose considerável de liberdade de atuação para os jornalistas e de estabilidade institucional, uma vez que o relato "objetivo" dos jornalistas não se faz em primeira pessoa, mas tem em vista, em boa medida, a perspectiva das instituições políticas e econômicas dominantes (e particularmente das instituições do governo) sobre os acontecimentos (Cook, 1998; Sparrow, 1999). Na ausência de tal estabilidade institucional, os jornalistas se veem obrigados a recorrer a estratégias de atuação inteiramente distintas daquelas que se tornaram modelares no ambiente do jornalismo anglo-americano. Um exemplo disto é fornecido pela análise de McCargo sobre o jornalismo na Tailândia. Em um contexto de grande instabilidade institucional, com sucessivas mudanças de governo, os jornalistas buscaram estabelecer relações próximas com o maior número possível de atores políticos: "Ao "descentralizar" a propriedade através da sub-contratação informal de espaço para um amplo espectro de colunistas ligados a diferentes interesses, o jornal pode adotar uma identidade camaleônica" (2003, p. 8-9). Está claro que a situação dos jornalistas durante o período Geisel não era idêntica à descrita por McCargo, pois a instabilidade estava firmemente restrita às alternativas situadas dentro do regime militar. De todo modo, a referência a este autor nos ajuda a perceber que as categorias originadas do ambiente anglo-americano não são suficientes para dar conta da complexidade da situação que tratamos de analisar aqui.

Assim, considerando a complexidade da situação que analisamos, utilizamos aqui quatro categorias analíticas, que descrevem diferentes maneiras pelas quais os jornalistas se posicionam frente aos acontecimentos que relatam. São elas a reprodução, a notícia factual, a notícia interpretativa e o comentário. Essas categorias dão conta de diferentes níveis de investimento dos jornalistas como intérpretes dos eventos que relatam. Esse investimento é mínimo no caso da reproducão literal dos pronunciamentos de personagens da notícia 2. A notícia constitui o centro da concepção moderna de jornalismo. Contudo, para os fins da nossa análise, é necessário distinguir dois tipos de notícias que têm consequências distintas do ponto de vista do envolvimento do jornalista. As notícias que denominamos factuais se limitam a descrever os acontecimentos, sem providenciar um quadro interpretativo que ajude a produzir sentido acerca deles, ao contrário do que ocorre com as noticias interpretativas ${ }^{3}$. No segundo caso os jornalistas atuam de modo muito mais ativo do que no primeiro. Finalmente, o comentário corresponde ao lugar de manifestação explícita da opinião, o que teoricamente implica em um grau suplementar de intervenção por parte dos jornalistas. Contudo, é importante ter em vista que, embora a opinião desempenhe um papel central no modelo que interpreta o jornalismo como uma forma de publicismo (Chalaby, 1998), no modelo de jornalismo americano - e por extensão no brasileiro, por conta da influência daquele sobre este - a opinião ocupa um lugar secundário, suplementar em relação à missão informativa do jornal. Neste caso, seria razoável sugerir que, no modelo americano de jornalismo as notícias interpretativas apontam para um modo mais ativo de intervenção do que o espaço da opinião.

\section{0 "31 de marco" entre 1974 e 1978}

As categorias de análise que propomos foram pensadas a partir da análise das matérias do jornal, que podem ser divididas em dois momentos: 1) matérias publicadas entre 1974 e 1977 e 2) matérias publicadas no ano de 1979. No primeiro momento, percebemos a coexistência de três das quatro categorias propostas reprodução, noticia factual e comentário. O segundo momento - embora não se descarte a possibilidade de aparecer algo das categorias anteriores - se apresenta como um corte pela presença de elementos que nos permitem identificar a quarta categoria adotada, que não havia aparecido até então - a notícia interpretativa. A seguir são discutidos os dois momentos propostos.

\section{4-1977}

O Globo, entre 1974 e 1978, transcreveu, sempre e na íntegra, os discursos do presidente Ernesto Geisel e as ordens do dia dos três ministros militares ${ }^{4}$. Eventualmente reproduzia partes de pronunciamentos de outros personagens, como foi o caso de uma mensagem "dirigida ao país" pelo ministro da Justiça, Armando Falcão em 31 de março de 1975 e de um discurso "de improviso" do Comandante do II Exército, Ednardo D’Avila Mello em 01 de abril do mesmo ano. A reprodução literal de discursos foi um recurso repetidamente usado pelo jornal durante todos os anos em questão, e ocupava uma parte considerável do espaço dedicado ao tema, o que fazia com que a função do jornal naquele momento se aproximasse da função reservada aos anais, ou seja, de uma reprodução anual para registro de fatos "fixos" que 
eram trazidos a público sem que se produzisse sentido sobre eles.

Até 1977 verifica-se a predominância da reprodução de falas aliada a uma cobertura cujo foco era exclusivamente o que se entendia pelo acontecimento. A partir disso é possível rascunhar algumas conclusões, ainda que provisórias. Em primeiro lugar

\section{fais maférias parecem mostrar que os jornalistas não enxergavam seu próprio papel como sendo de interpretadores dos fatos, mas sim de estenógrafos ou publicizadores de notícias 5 .}

Esse status é reforçado, por exemplo, pela inexistência de entrevistas. A reprodução de falas oficiais, de pronunciamentos nacionais, sem que houvesse diálogo com os repórteres ou espaço para perguntas, em torno das cerimônias, ou interpretações acerca do sentido que lhes poderia ser atribuído que diferenciassem as matérias de um ano para outro mostra que a narração de um movimento previamente definido pelo cerimonial militar bastava naquele momento para construir a notícia. As vozes consideradas anualmente nas matérias eram basicamente as mesmas, com poucas alterações, não incluíam a voz do próprio jornalista, e geralmente reiteravam as mesmas opiniões acerca do movimento. A metáfora do espelho - considerar a "notícia como uma reflexão mais ou menos literal do curso dos acontecimentos" (Hallin \& Mancini, 1993, p. 306) -, pode ser explicada, tanto do ponto de vista dos próprios jornalistas, quanto dos chefes de governo, como um recurso eficiente para se proteger contra críticas políticas. Assim, a reprodução na íntegra das falas do presidente e dos ministros, se significava por um lado um artifício por meio do qual o jornalista se protegia, significava também que, para isso, minimizava sua autoridade. A figura a seguir, retirada do jornal, ilustra o que chamamos de reprodução de falas n'O Globo.

\section{Sylvio Frota: Militares têm compromisso de honra}

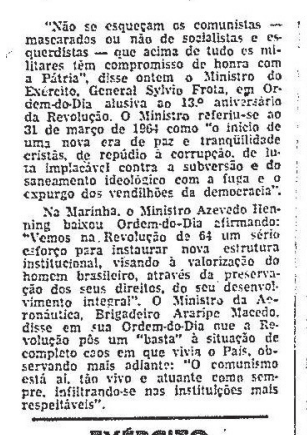

EXERCITO
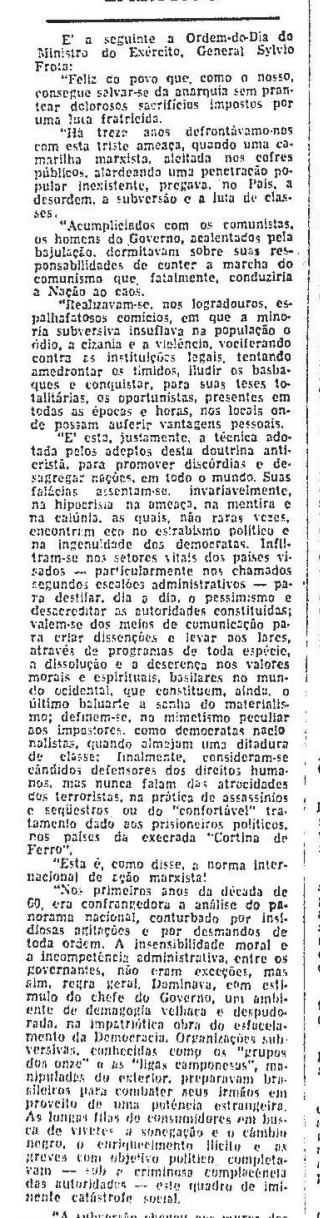

(1)

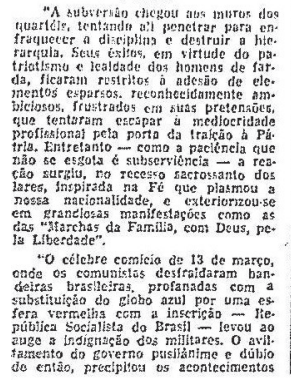

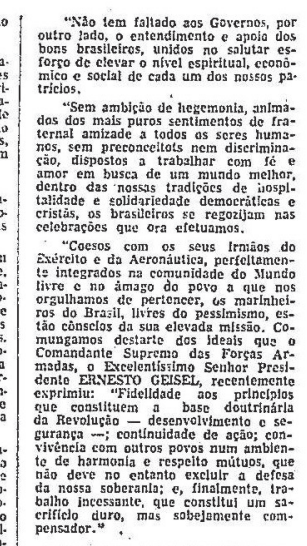

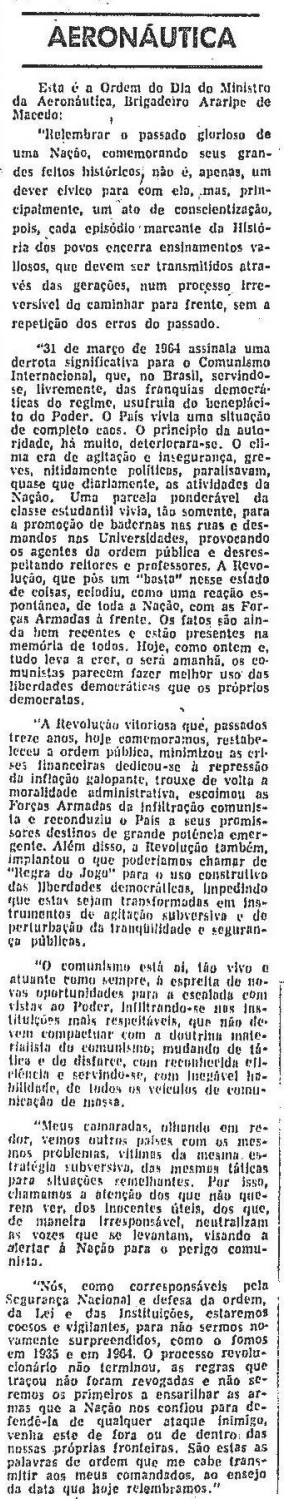


Ao mesmo tempo em que reproduzia os discursos desses atores políticos, entre 1974 e 1977, O Globo tratava as matérias sobre os aniversários da "Revolução" militar de 1964 não como acontecimentos jornalísticos, mas como sendo acontecimentos rituais. As cerimônias que ocorreriam a cada dia 31 de março - data comemorativa apontada pelos militares ${ }^{6}$-, entre 1974 e 1976, foram retratadas em notícias factuais pelo menos desde o dia anterior até o dia posterior, ou seja, eram mencionadas já nos dias 30 de março, confirmadas nos dias 31 e ainda lembradas nos dias 01 de abril. Entre 1977 e 1978 as menções se concentravam nos dias 31 de março e 01 de abril. As matérias cuja publicação antecedia o dia 01 de abril tinham caráter de previsão e pretendiam antecipar (30/03) e reafirmar (31/03) a programação que seria realizada. Nos dias seguintes aos eventos (01/04) era, então, noticiado o que de fato havia acontecido. Eram basicamente seguidos os passos do presidente Geisel durante as comemorações, retratando onde ele estaria, o que estaria fazendo e em que horário. Assim, as matérias apresentavam geralmente, até 1977, uma linguagem referencial (Hallin \& Mancini, 1993) ${ }^{7}$, com ênfase na descrição dos acontecimentos, como mostra o trecho a seguir.

BRASÍLIA (O GLOBO) - Uma cerimônia na Vila Militar, no Rio, na parte da manhã, com a presença do presidente Geisel, será a principal solenidade de hoje nas comemorações do $12^{\circ}$ aniversário da Revolução. $\mathrm{O}$ presidente, que chegará ao Rio às $9 \mathrm{~h} 30 \mathrm{~m}$, acompanhado dos generais Hugo de Abreu e João Batista de Figueiredo, ministros-chefes do Gabinete Militar e do SNI, almoçará na Vila Militar e embarcará às 14 horas, na Base Aérea do Galeão, de volta à Brasília. $[\ldots]^{8}$

Embora saibamos que o trecho acima surgiu de uma série de escolhas - por exemplo, do que falar e de quem falar, já que o próprio recorte é determinado pelo ponto de vista de quem o constrói -, fica claro mais uma vez a minimização da presença do jornalista, quando a rotina de uma cerimônia é simplesmente transcrita. Ainda entre 1974 e 1977, nota-se, em todos os anos, a publicação de boxes de comentário, como se fossem quadros à parte e não tivessem relação com as matérias de cobertura das cerimônias, cuja linguagem era extremamente opinativa. Neles comentava-se o papel e a importância da revolução de 1964, como se vê no exemplo intitulado Fidelidade às origens:
A REVOLUÇÃO de 1964 nasceu de uma soma nacional de vontades contrárias ao processo de desintegração instalado no País, sob as vistas cúmplices de um governo alcançado na sua autoridade e incapaz sequer de conduzir a sua própria opção antidemocrática. [...] A partir de certo momento, o "status" institucional vigorante passou a servir exclusivamente como dispositivo de proteção do esquema de dissolvência, imprimindo fisionomia de estado de direito ao processamento galopante da subversão oficializada. [...] A iniciativa militar se incumbiu de punçar o tumor e o ato de medicina democrática preventiva encontrou no ânimo dominante da Nação uma receptividade dificilmente comparável - em carga e sintonia - nos anais da nossa História. [...] ${ }^{9}$

Não há dúvidas de que esses quadros opinativos, constantemente presentes durante o período, falam sobre as tendências políticas do jornal. Mas, o fato desses quadros aparecerem separados das matérias que cobriam o evento, num espaço declaradamente dedicado à opinião, torna menos relevante gastar tempo para denunciá-los como "governismo" - algo que já se sabe - do que analisar porque as matérias são construídas por meio de outra linguagem e que linguagem é essa.

Como se pode notar, formas diversas foram adotadas e coexistiram no jornal para contar sobre o contexto político pelo qual se passava. Se por um lado O Globo reservava um quadro espacialmente separado das matérias em que oferecia comentários indubitavelmente parciais e simpáticos ao regime militar, por outro, a cobertura das cerimônias de aniversário da revolução eram integralmente referenciais, atuando os jornalistas como estenógrafos ou meros publicizadores da rotina das cerimônias. $\mathrm{O}$ papel dos jornalistas na ocasião não é entendido como o de explicadores que devem interpretar a realidade política antes de oferecê-la aos leitores.

\section{8}

Essa situação manteve-se constante entre 1974 e 1977. A cobertura das cerimônias militares apresentava caráter meramente descritivo, transcrevendo os passos do presidente, as vozes dos personagens militares e as etapas das comemorações. Porém, na cobertura das solenidades do ano de 1978 identificamos uma considerável diferença com relação ao período anterior. Essa diferença torna-se explícita se compararmos duas 
matérias, uma publicada em 31 de março de 1978, sobre a comemoração do $14^{\circ}$ aniversário da revolução de 1964, que se caracterizava por apresentar uma notícia interpretativa ao contrário do que aconteceu nos anos anteriores, e outra, de 31 de março de 1977, que apresenta a linguagem referencial, descritiva e cronológica de que falamos. Abaixo são reproduzidas partes dessas duas matérias.

\section{Geisel comemora Revolução na Vila Militar}

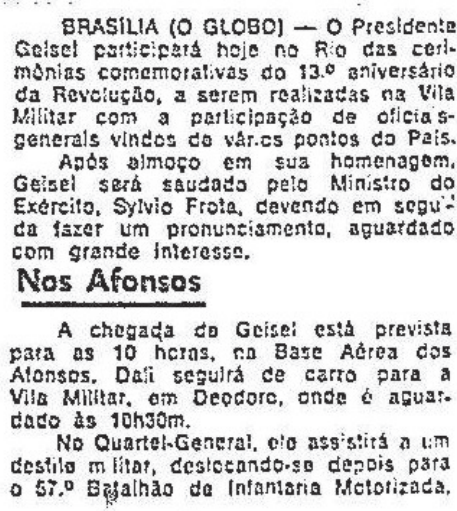

conde pallicipara de um coquetal e man. tera palcstra fntormal com cs coman dantes militares do vatias tegioes do pais. o Presidenta sera cumptimentaso, a entreda do salzo ondo será servico o a!mç̧o, pelos corond 5 qus comandam unidades sodiudas na vila Miltar e que ismbés patticipasăo do ericontro.

\section{Na Tijuea}

Deixando a Vita Hiliter em héloop :2:0 da FA3. Geisel cesembarcard no E5 tásio Matoo Fitho. no Maraesna. da'i seguinzo de carro para o novo Centro de Alibidades Recreativas do Sete - Serviço Sezial do Caméteio. na Rua Batdo 60 Lesquita, cheganco as $14 \mathrm{hatom}$ o sendo recobido peics dlsigentes da entidade."

Dapcis do ouv t discurso do piezi. dento to Sere, descoratá placa cemomo.

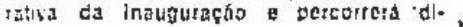

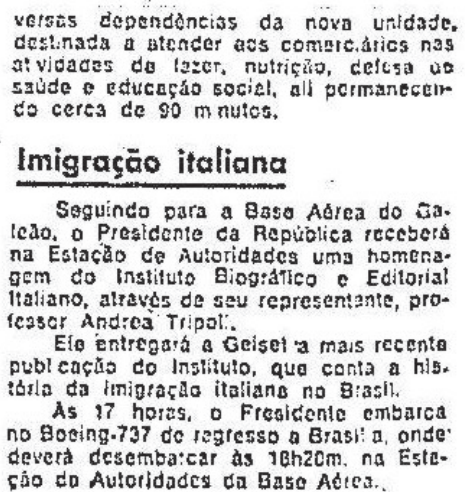

velaths dependenciss da nova unidaje. at vidaces do lazer nuttiç?o, defcsa uo sude e edtucaça socisl, alt pormanectir

Seguindo para a Baso Aerea do sa. lea. o Preatdente ea Repiraliea recebert gem do instituto Qiog:d7seo e Editorial lialiano, altaves de seu representante, proEndiea Tripol publ caçŭo to Insituto qua conta a his. Brla da imigeaça italiane no B:asil. no gosing.737 do . Fotess cáo da Autoridades da Baso Ader.

Figura 2 - O Globo, 31 de março de 1977, p. 12.

\section{Geisel discursa hoje mas ênfase não é política}

BRASILIA 10 GLOBOI - O Presidente Ernesto Geisel vai fazer hoje, no Clabe de Aeronáutica, um discurso peta passagem do 149 aniversútio da RevoIuçio de 3i de intarço que, segundo fon. tes ligadas à presidëncin, năo deverà registrar nenluum avanço em relnçĩo a pronunciamentos anteriores, guanto ì abertura politlea. O lliscurso tera un: sentido de afirnaçào revoluclonaria, ressaltando a importancia, as conquistas e os objetivos do movimento de Mlarco de 64.

Geisel falarii em um a]moşo tio qua] partieiperàn 1 io autoridades militares e eivis. 0 discurso de Gelsel seri trans. mitido pela "Voz do Brasil" e por uma cadeia uacional de televisäo, formada a partir das 20 horas.

\section{Exalsaçāo}

A reafirmacio da dispoxiçin do Pre. sidente $\mathrm{cm}$ altunçar, atraves do conben. so entre os partjdos, a aperfeiçoamentn das institujecoes politleas ê o móximo que se espera do pronunciamento em rela. ção ḋs refornıss. Essa parte, contictlir, ñ̄o seria a enfase da fala presidencial, mas a cxaltậño da Revoluçắo de Atar. mas de 1004 .

0 fato politico mais signifleatixn dit comemornęüo da Revoluçầ, na clube da Aeronatillen, serú, para nlguns diriEentes da Arena, a particjpaçáo -- pela primeira ver nestes 14 anos - de ci. vis. Esse fato ansenizaria, segundo es. sas fantes, eventuais frustraçies dos que. otimistas, esperam importantes indíle: çóes de abertura politica na fala présidencial.
Figura 3 - O Globo, 31 de março de 1978, p. 5.

Conforme se nota, em 1978, ao contrário do ano anterior, o jornal se esforça para oferecer aos leitores uma interpretação do fato reportado. Essa mudança de posicionamento mostra que os jornalistas deixam de se apresentar como reprodutores, como repetidores de fatos que visam reiterar um determinado formato de visão de mundo, para assumir a posição de analistas experientes do mundo politico (Schudson, 1993, p. 281). O Globo, neste momento, se permite fornecer interpretações acerca da política que não haviam tido lugar desde 1974. A principal mudança se relaciona a abordagem usada para falar sobre o pronunciamento do presidente Ernesto Geisel. Em vez de narrar todos os passos que seriam tomados pelo presidente durante a comemoração, o jornal lança interpretações sobre o que se poderia ou não esperar do discurso do presidente em relação aos discursos dos anos anteriores e fornece espaço para a inserção de opiniões de outros personagens civis que não costumavam aparecer nas matérias.

Outro ponto digno de nota é que pela primeira vez percebe-se a presença um assessor [militar] de imprensa. Conforme a continuação da matéria:

[...] O assessor de imprensa da Presidência da República, coronel Toledo Camargo, disse ontem que entre os convidados para o almoço no Clube da Aeronáutica - que terá inicia às 12 horas - estão a totalidade dos oficiais-generais de quatro estrelas das três Forças Armadas e os demais oficiais-generais com funções na capital [...] (O Globo, 31 de março de 1978, p. 5). 
O fato da figura do assessor ter aparecido na matéria, pela primeira vez desde 1974, e de terem sido consultados outros personagens civis aos quais foram demandadas interpretações acerca do ritual político demonstra um esforço do jornal de recolher vozes e leituras do mundo político que não era verificado anteriormente.

\section{0 que forna importante ressalfar o fom interpretativo então assumido é a consideração de que é especialmente na interpretaç̃o que o jornal está realmente produzindo sentido e construindo uma narrativa, ou seja, desempenhando um papel ativo de intérprete do mundo político.}

É também especialmente debruçando-se sobre um texto interpretativo que se pode perceber a complexidade da construção da notícia. As tomadas de posição, embora camufladas pelo trânsito de diferentes vozes, são, enfim, não apenas reproduzidas, mas produzidas e reiteradas de diferentes formas. Sendo este um caminho para entender como o jornal mudou durante o regime militar e que estratégias foram empregadas naquele período, volta-se à questão da importância de considerar a atuação não dicotômica e complexa da grande imprensa no período considerado.

\section{Considerações finais}

A análise realizada sobre as matérias do jornal O Globo referentes às solenidades de comemoração do aniversário da "revolução" militar, entre 1974 e 1978, permitiu, neste início das pesquisas, verificar que certas categorias distintas entre si coexistiram na forma das notícias e informações publicadas. Permitiu perceber também um claro corte em 1978, com a publicação de uma matéria de tom bastante diferente dos anos anteriores, uma matéria em que o jornalista enfim assumia o papel de interpretar aquele determinado contexto político, em oposição às notícias factuais precedentes.

Essa distinção da intensidade com que o "eu" que fala (o jornalista) aparece ao longo do tempo, permite considerar que a matéria de 1978 uma autoridade jornalística muito maior do que a que tinha no período anterior. Talvez não seja mera coincidência que essa distinção comece aos poucos a surgir justamente no decorrer dos anos em que se inicia a distensão política do regime militar autoritário que vigorava no país. No entanto, mais do que entender essa mudança apenas como fruto do fim da repressão, devemos vê-la como um esforço de negociação do jornal enquanto mediador em meio a um contexto ambíguo e tenso, marcado por projetos concorrentes de governo em que o futuro era incerto e em que não saberia qual "facção" triunfaria.

Nos anos 1950 o jornalismo brasileiro passou por uma reforma, que teve dentre as suas consequências a adoção do ideal da objetividade. Ainda que até hoje se coloque essa objetividade em evidência quando se fala do regime militar iniciado em 1964 a classificação dada à imprensa continua se resumindo a imprensa "governista" em oposição à imprensa alternativa.

\section{Por que continuar a tratar a imprensa no regime militar somente de forma dicotômica sem analisar de que forma ela se posiciona, inferage com a polífica e se torna sua mediadora perante a sociedade?}

Enquanto isso muitas questões ainda precisam ser feitas. O presente texto pretendeu iluminar algumas dessas outras questões. Partindo das narrativas do jornal sobre as solenidades de aniversários do golpe militar nos foi possível perceber que papel o jornalista reservava para si enquanto mediador da realidade política e como esse papel é passível de mudanças no tempo que não se devem somente às mudanças de regime. Espera-se assim acrescentar questões ao estudo da mediação no jornalismo, já que as mudanças ocorridas com o passar do tempo na forma de reportar um acontecimento não se devem apenas a mudanças no próprio acontecimento, mas na necessidade de se atualizar papéis assumidos na interação entre os jornalistas e os contextos complexos e mutáveis que os cercam.

\section{REFERÊNCIAS}

ABREU, Alzira Alves de. A mídia na transição democrática brasileira. Sociologia - Problemas e Práticas, 
n. 48, p. 53-65, 2005.

ABREU, Alzira Alves de; LATTMAN-WELTMAN, Fernando. Uma instituição ausente nos estudos de transição: a mídia brasileira. In: ABREU, Alzira Alves de (Org). A democratização no Brasil: Atores e Contextos. Rio de Janeiro: Editora FGV, p.67-101, 2006.

ABREU, Alzira Alves de; LATTMAN-WELTMAN, Fernando. Momentos de decisão: os anos 70 e a mídia no Rio de Janeiro. In FREIRE, Américo; SARMENTO, Carlos Eduardo B.; MOTTA, Marly Silva da (Org.). Um estado em questão - Os 25 anos do Rio de Janeiro. Rio de Janeiro: Editora FGV, 2001.

ABREU, Alzira Alves de; LATTMAN-WELTMAN, Fernando; ROCHA, Dora (Org.). Eles mudaram a Imprensa. Rio de Janeiro: Editora FGV, 2003.

ALBUQUERQUE, Afonso de. Um Outro Quarto Poder: Imprensa e Compromisso Político no Brasil. Revista Contracampo, n. 4, 2000.

ALBUQUERQUE, Afonso de. Aconteceu num Carnaval: algumas observações sobre o mito de origem do jornalismo brasileiro moderno. Eco-Pós, UFRJ, v. 11, p. 95-116, 2009.

ALBUQUERQUE, Afonso de; SILVA, Marco Roxo da. Skilled, Loyal and Disciplined: Communist Journalists and the Adaptation of the American Model of "Independent journalism" in Brazil. International Journal of Press/Politics, v.14, n.3, p. 376-395, jul. 2009.

ANDRADE, Evandro Carlos de. Entrevista. In: ABREU, Alzira Alves de; LATTMAN-WELTMAN, Fernando; ROCHA, Dora (Org.). Eles mudaram a Imprensa. Rio de Janeiro: Editora FGV, 2003.

CASTRO, Celso. A Invenção do Exército Brasileiro. Rio de Janeiro: Jorge Zahar, 2002.

CASTRO, Celso. Comemorando a "revolução" de 1964: a memória histórica dos militares brasileiros. In FICO, Carlos [et al.]. Ditadura e democracia na América Latina: balanço histórico e perspectivas. Rio de Janeiro: Editora FGV, 2008.

CHALABY, Jean K. Journalism as an Anglo-American Invention: A Comparison of the Development of French and Anglo-American Journalism, 1830s-1920s. European Journal of Communication, v. 11, n.3, p. 303-326, 1996.

CHIRIO, Maud. Fêtes nationales et régime dictatorial au Brésil. Vingtième Siècle. Revue d'histoire, n. 90, p.89-108, 2006.

COOK, Timothy E. Governing with the News. The News Media as a Political Institution. Chicago, University of Chicago Press, 1998.

COOK, Timothy E. The News Media as a Political Institution: Looking Backward and Looking Forward. Political Communication, n. 23, p. 159-171, 2006.
DASSIN, Joan. The Brazilian Press and the Politics of Abertura. Journal of Interamerican Studies and World Affairs, v. 26, n. 3, p. 385-414, 1984.

DUARTE, Celina Rabello. 1983. Imprensa e Redemocratização no Brasil. Dados - Revista de Ciências Sociais, v. 26, n. 2, pp. 181-195.

FLUSSER, Vilém. A filosofia da caixa preta: ensaios para uma futura filosofia da fotografia. Rio de Janeiro: Relume Dumará, 2002.

FLUSSER, Vilém. O universo das imagens técnicas - Elogio da superficialidade. São Paulo: Annablume, 2008.

GUIMARÃES, Cesar; VIEIRA, Roberto A. A. A televisão brasileira na transição: um caso de conversão rápida à nova ordem. Rio de Janeiro: IUPERJ, 1985.

HALLIN, Daniel; MANCINI, Paolo. Comparing Media Systems: Three Models of Media and Politics. Cambridge: Cambridge University Press, 2004.

HALLIN, Daniel; MANCINI, Paolo. Falando do Presidente: A Estrutura Política e a Forma representacional nas notícias televisivas dos Estados Unidos e da Itália. In: TRAQUINA, Nelson (Org.). Jornalismo: Questões, Teorias e "Estórias". Lisboa: Editora Vega, 1993.

HOLZBACH, Ariane Diniz. Gente de toda parte foi ver o exmetalúrgico virar Presidente da República - A narrativa da posse de Lula na Folha de São Paulo e em O Globo. 2008. Dissertação. (Mestrado em Comunicação Social) - Programa de PósGraduação em Comunicação, UFF, Niterói, 2008.

KERTZER, David. Ritual, Politics, and Power. New Haven and London: Yale University Press, 1988.

LATTMAN-WELTMAN, Fernando. Mídia e transição democrática: a (des)institucionalização do panóptico no Brasil. In ABREU, Alzira Alves de; LATTMANWELTMAN, Fernando; KORNIS, Mônica de Almeida. Mídia e Política no Brasil: jornalimo e ficção. Rio de Janeiro: FGV, 2003.

MARTINS, Luciano. A 'Liberalização' do Regime Autoritário no Brasil. In: O’DONNEL, Guillermo; SCHMITTER, Philippe; WHITEHEAD, Laurence (org.). Transições do Regime Autoritário: América Latina. São Paulo: Vértice, Editora Revista dos Tribunais, 1988.

MCCARGO, Duncan. Media and Politics in Pacific Asia. Londres e Nova Iorque: Routledge Curzon, 2003.

PORTO, Mauro P. Mass media and politics in Democratic Brazil. In: KINZO, Maria D'Alva; DUNKERLEY, James. Brazil since 1985: Economy, polity an society. Londres: Institute of Latin American Studies (University of London), 2003.

RESENDE, Fernando. O Discurso Jornalístico Contemporâneo: Entre o Velamento e a Produção das Diferenças. Revista Galáxia, São Paulo, n.14, p.81-93, 2007. 
SCHUDSON, Michael. Discovering the News. New York: Basic Books, 1978.

SCHUDSON, Michael. A Política da Forma Narrativa: A Emergência das Convenções Noticiosas na Imprensa e na Televisão. In: TRAQUINA, Nelson (Org.). Jornalismo: Questões, Teorias e "Estórias". Lisboa: Editora Vega, p. 279293, 1993.

SCHUDSON, Michael. Question Authority: A History of the News Interview. In: SCHUDSON, Michael. The Power of News. Cambridge, Harvard University Press, 1995.

SOARES, Glaucio Ary Dillon. A censura durante o regime autoritário. Revista Brasileira de Ciências Sociais, v.4, n.10, p.21-43, jun.1989.

SPARROW, Bartholomew H. Uncertain Guardians. The News Media as a Political Institution. Baltimore e Londres: The Johns Hopkins University Press, 1999.

SPARROW, Bartholomew H. A Research Agenda for an Institutional Media. Political Communication, n. 23, p. 145157, 2006.

STEPAN, Alfred. Os militares: da Abertura à Nova República. Rio de Janeiro: Paz e Terra, 1986.

TUCHMAN, Gaye. A Objectividade Como Ritual Estratégico: uma análise das noções de objectividade dos jornalistas. In TRAQUINA, Nelson (Org.). Jornalismo: Questões, Teorias e "Estórias". Lisboa: Editora Vega, p. 7490, 1993.

WHITE, Hayden. The Value of Narativity in the Representation of Reality. In: MITCHELL, W. J. T. (ed.). On Narrative. Chicago: The University of Chicago Press, 1980.

ZELIZER, Barbie. Covering the Body: The Kennedy Assassination, the Media, and the Shaping of Collective Memory. Chicago: The University of Chicago Press, 1992.

\section{NOTAS}

1 Herzog foi torturado e morto nas dependências do II Exército, em São Paulo, após ter sido preso sob a acusação de ser ligado ao Partido Comunista Brasileiro, em outubro de 1975.

2 É preciso distinguir a reproducão, parcial ou integral do discurso de um personagem pelo jornal, da citação. Neste caso, a fala do personagem é apropriada pelo jornalista como a evidência de um argumento desenvolvido por ele, o que indica um grau considerável de autonomia por parte do jornalista. Sobre a importância das citações no texto jornalístico ver Tuchman (1993).

3 Pode-se dizer que a relação entre notícias factuais e notícias interpretativas é análoga à que White traça entre os anais e o relato historiográfico.

4 Os ocupantes dos três cargos de ministros militares do governo Geisel foram: Vicente de Paulo Dale Coutinho
(15/03/74 a 27/05/1974), Sylvio Frota (28/05/1974 a 12/10/1977), Fernando Belfort Bethlem (12/10/1977 a 15/03/1979) - Exército-; Geraldo Azevedo Henning (15/03/1974 a 15/03/1979) - Marinha- e Joelmir Campos de Araripe Macedo (15/03/1974 a 15/03/1979) - Aeronáutica. Conforme datas que constam na galeria dos presidentes, na página do Planalto. Disponível em: <http://www.planalto.gov.br/Infger_07/presidentes/ ernesto_geisel.htm>. Acesso em 22 nov. 2009.

5 Esta discussão é bem realizada, em outro contexto, por Schudson (1993).

6 Enquanto para alguns setores da sociedade, que consideram o evento um golpe, a data do movimento militar foi 1 de abril, para os militares, que não desejavam ver seu movimento ligado ao "dia da mentira", a data "oficial" passou a ser o 31 de março.

7 Hallin e Mancini chamam de "referencial" o relato da TV italiana RAI TG1 sobre determinado episódio, em comparação com relatos de TV norte-americanos sobre o mesmo período, explicando que enquanto "o relato americano é tanto estória como interpretação", o relato italiano "não oferece significado em si próprio, mas envia o espectador noutra direção: fornece uma revista, uma lista de interpretações oferecidas pelos atores políticos fora do jornalismo" (Hallin \& Mancini, 1993, p. 313-314).

8 O Globo, 31/03/1976, p. 3.

9 O Globo, 31/03/1974, p. 1. 